\title{
HUBUNGAN ANTARA PENYESUAIAN SOSIAL DENGAN INTERAKSI TEMAN SEBAYA PADA MAHASISWA BK UKSW ANGKATAN 2017
}

\author{
Vincencia Elva Putri Rimardhanty ${ }^{1}$, Tritjahjo Danny Soesilo ${ }^{2}$, Yari Dwikurnaningsih ${ }^{3}$ \\ Email:132015056@student.uksw.edu ${ }^{1}$,Tritjahjo.danny@uksw.edu², \\ yari.dwikurnaningsih@staff.uksw.edu ${ }^{3}$ \\ Program Studi Bimbingan dan Konseling FKIP Universitas Kristen Satya Wacana, ${ }^{1,2,3}$
}

\begin{abstract}
Abstrak
Penelitian ini bertujuan untuk menentukan signifikansi hubungan antara penyesuaian sosial dan interaksi teman sebaya pada mahasiswa Bimbingan dan Konseling UKSW 2017. Subjek penelitian ini adalah mahasiswa Bimbingan dan Konseling UKSW 2017 yang berjumlah 50 siswa. Pengumpulan data menggunakan skala penyesuaian sosial yang dinyatakan oleh Hurlock (1999) dengan jumlah item 43 pernyataan dan skala interaksi teman sebaya yang dinyatakan oleh Papalia (2009) dengan jumlah item 39 pernyataan. Penelitian ini menggunakan metode korelasi, sedangkan teknik analisis data Kendall tau $b$. Hasil penelitian menunjukkan bahwa ada hubungan yang signifikan antara penyesuaian sosial dan interaksi teman sebaya pada mahasiswa Bimbingan dan Konseling UKSW 2017 dengan koefisien korelasi $\mathrm{r}=0,782$ dan $\mathrm{p}=$ $0,000<0,05$. Ini menunjukkan semakin tinggi penyesuaian sosial, semakin tinggi tingkat interaksi teman sebaya, atau sebaliknya semakin rendah penyesuaian sosial, semakin rendah tingkat interaksi teman sebaya.

Kata Kunci: Penyesuaian Sosial, Interaksi Teman Sebaya
\end{abstract}

Abstract
This research aims to determine the significance of relationship between social adjusment and peer interaction on Guidance and Counseling's $2017^{\text {th }}$ Student of UKSW. The subject of this research is Guidance and Counseling's 2017 $7^{\text {th }}$ Student of UKSW totaling 50 students. Data collection using adjusment social's scale stated by Hurlock (1999) with the number of items 43 statements and peer interaction's scale stated by Papalia (2009) with the number of items 39 statements. This research uses the method of corellation, while the technique of data analysis kendall tau $b$. The result showed that there is a significant relationship between social adjustment and peer interaction on Guidance and Counseling's Student of UKSW 2017 $7^{\text {th }}$ with corellation coefficient $r=0.782$ and $p=0.000<0.05$. It showed the higher the social adjustment, the higher the peer interaction rate, or conversely the lower the social adjusment, the lower the peer interaction rate.

Keywords: Social Adjusment, Peer Interaction

\section{PENDAHULUAN}

Manusia adalah makhluk sosial. Sebagai makhluk sosial, individu yang memiliki hubungan dengan individu lain perlu memiliki aturan, nilai dan norma sosial yang ada pada masyarakat dimana individu tersebut berada. Adanya keanekaragaman budaya menuntut individu untuk bisa menyesuaikan diri dengan lingkungannya sebagai cara untuk berkomunikasi dan berinteraksi. Manusia dituntut untuk membentuk suatu perkumpulan dan organisasi untuk mendukung eksistensi dan peran kehidupannya. Menurut Hurlock (1999), penyesuaian sosial adalah keberhasilan seseorang untuk beradaptasi dengan orang lain dalam satu kelompok. Secara umum, perilaku manusia sangat sedikit dipengaruhi oleh insting dan refleks, tetapi justru banyak dipengaruhi oleh halhal yang telah dipelajarinya. Dalam hal 
ini individu tidak memiliki kekhususan. Individu dapat belajar berperilaku tertentu dalam suatu lingkungan sampai dapat bertahan.

Menurut Rufaida (2017), dalam hubungan interaksi sosial yang terdapat di dalam kelompok teman sebaya, biasanya antara satu dengan yang lain dapat saling mempengaruhi. Hal ini sesuai dengan pendapat $H$. Bonner (dalam Dian, 2014) bahwa interaksi sosial adalah hubungan antara dua atau lebih individu dimana sifat dan karakteristik individu satu dapat mempengaruhi, mengubah, atau memperbaiki sifat dan karakteristik individu yang lain ataupun sebaliknya.

Berdasarkan hasil observasi dan wawancara yang telah dilakukan pada bulan Juni 2018 dengan 3 orang mahasiswa Bimbingan dan Konseling UKSW angkatan 2017, peneliti menemukan fenomena yang menunjukkan bahwa masih terdapat mahasiswa dalam masa perkembangan remaja yang kesulitan dalam bekerjasama dan menjalin hubungan dengan orang lain. Fenomena lain juga terlihat bahwa masih banyak mahasiswa yang tidak terbuka dengan teman sebayanya, kurang mampu menyelesaikan masalah bersama sehingga tak jarang mahasiswa yang menyendiri baik di dalam kelas maupun di luar kelas. Dengan adanya fenomena tersebut menimbulkan suatu persoalan terutama mengenai penyesuaian sosial dan interaksi teman sebaya. Padahal mahasiswa BK nantinya akan menjadi konselor atau guru BK dimana kompetensi guru BK ada pada bidang sosial.

Mahasiswa yang kesulitan dalam berinteraksi lebih dominan muncul pada anak yang berbakat. Munandar (dalam Fitoko, 2010) mengatakan bahwa anak yang berbakat memiliki ciri-ciri sukar bergaul dengan teman-temannya dan sukar berinteraksi dengan lingkungannya. Anak berbakat biasanya lebih senang berteman dengan teman yang sama-sama pintar dalam kondisi akademik. Sementara kecenderungan berinteraksi dengan teman yang lain semakin rendah. Kesulitan berinteraksi dengan teman sebaya yang dialami beberapa mahasiswa BK angkatan 2017 tersebut menunjukkan adanya kesenjangan konsep awal dimana seharusnya penyesuaian sosial merupakan faktor yang mempengaruhi interaksi teman sebaya. Namun dalam fenomena yang terjadi masih terdapat mahasiswa yang sulit untuk bekerjasama dan menjalin hubungan dengan orang lain terutama dengan teman sebaya. 
Dalam penelitian sebelumnya oleh Hastuti (2015) tentang Hubungan Antara Interaksi Teman Sebaya dengan Penyesuian Sosial di SMPN 2 Surakarta dengan $r=0,508$, sign $=0,001(<0,05)$. Hal ini berarti bahwa ada korelasi positif antara interaksi teman sebaya dengan penyesuaian sosial, yang artinya semakin tinggi individu berinteraksi dengan teman sebayanya, semakin tinggi pula ia dapat menyesuaikan diri dengan lingkungan sosial. Namun penelitian berbeda dilakukan oleh Dian (2014) dengan judul Hubungan Antara Interaksi Teman Sebaya dengan Kemampuan Sosialisasi Siswa Kelas IX SMP Negeri 2 Pabelan Tahun Pelajaran 2014/2015, karena didapatkan hasil bahwa tidak ada hubungan yang signifikan antara penyesuaian sosial dengan interaksi teman sebaya atau dengan kata lain berkorelasi negatif. Dibuktikan dalam uji hipotesis didapatkan hasil $\mathrm{r}=-0,017, \mathrm{p}=$ 0,846 . Hal ini juga berarti bahwa belum tentu semakin tinggi interaksi dengan teman sebaya maka semakin tinggi pula penyesuaian sosial.

Berdasarkan penjelasan dan beberapa penelitiandi atas, maka peneliti tertarik untuk melakukan penelitian dalam rangka membuktikan adakah hubungan yang signifikan antara penyesuaian sosial dengan interaksi teman sebaya dengan mengangkat judul "Hubungan Antara Penyesuaian Sosial dengan Interaksi Teman Sebaya Pada Mahasiswa Bimbingan dan Konseling FKIP UKSW angkatan 2017”.

\section{KAJIAN PUSTAKA \\ Interaksi Teman Sebaya}

Menurut Santrock (dalam Hasan dan Handayani, 2014), seorang anak banyak menghabiskan waktu bersama temantemannya di sekolah, sehingga dapat dilihat peranan teman sebaya dalam kehidupan anak. Pengaruh teman sebaya juga dapat menjadi positif ataupun negatif. Menurut Gunarsa (dalam Kartika, 2004), semakin bertambah umur, anakanak makin memperoleh kesempatan lebih luas untuk mengadakan hubungan dengan teman bermain sebaya.Interaksi teman sebaya merupakan hubungan individu dengan kelompoknya yang ratarata usia anggota kelompok tersebut hampir sama (Pierre, 2005). Interaksi teman sebaya biasanya mencakup kerjasama, keterbukaan dan pengaruh antara tiap anggota dalam satu kelompok. Perasaan tertarik atau sikap positif terhadap teman dalam satu kelompok adalah suatu dasar adanya perkembangan hubungan teman sebaya. Interaksi teman sebaya adalah satu faktor penting dalam 
kehidupan remaja. Teman sebaya dapat menjadi dasar adanya kontak sosial dan mewujudkan nilai-nilai yang ada di dalamnya. Menurut Setiawati dan Suwarno (2010), interaksi dengan teman sebaya akan membuka pandangan baru pada anak dan memberi kebebasan kepada mereka untuk membuat keputusan Selain itu teman sebaya juga berpengaruh dalam berbagai konteks prinsip kerja, tanggungjawab bersama dan persaingan yang sehat untuk mencapai tujuan.

Berdasarkan beberapa pengertian mengenai interaksi teman sebaya, maka dapat diambil kesimpulan bahwa interaksi teman sebaya merupakan hubungan sosial antar individu yang ratarata memiliki usia yang sama, serta di dalamnya terdapat keterbukaan, kerjasama, tujuan, serta frekuensi hubungan yang sama sehingga dapat mempengaruhi individu satu sama lain.

Terdapat aspek-aspek interaksi teman sebaya yang dikemukakakan oleh Papalia (2009) adalah sebagai berikut:

1. Komunikasi Antar Teman Sebaya

Komunikasi merupakan suatu proses penyampaian dan penerimaan lambing-lambang yang mengandung arti, baik yang berwujud informasi, pemikiran, pengetahuan, maupun yang lainnya.
2. Adaptasi

Dalam interaksi ada kemungkinan individu dapat menyesuaikan diri dan beradaptasi dengan yang lain atau sebaliknya.

3. Konformitas

Konformitas merupakan tekanan atau tuntutan untuk mengikuti temanteman sebayanya dan ini dapat bersifat positif maupun negatif

Berdasarkan uraian di atas dapat dikatakan bahwa yang merupakan aspekaspek interaksi teman sebaya adalah komunikasi antar sebaya, penyesuaian diri terhadap teman, dan tuntutan konformitas.

\section{Penyesuaian Sosial}

Menurut Scheineders (dalam Aristya, 2018) penyesuaian diri adalah suatu proses yang meliputi respon mental dan perilaku, dalam hal ini individu akan berusaha mengatasi ketegangan, kebutuhan, dan konflik yang berasal dari dalam dirinya dengan baik dan menghasilkan derajat kesesuian antara tuntutan yang berasal dari dalam dirinya dengan dunia yang obyektif tempat individu hidup. Menurut Hurlock (1999) penyesuaian sosial merupakan keberhasilan seseorang untuk dapat menyesuaikan diri dengan orang lain terutama dalam kelompok. Hurlock 
(dalam Estiane, 2015) mengungkapkan bahwa salah satu tugas perkembangan masa remaja yang paling sulit berhubungan dengan penyesuaian sosial. Pada dasarnya, manusia adalah makhluk sosial yang selalu menjadi bagian dari lingkungan tertentu. Gerungan (dalam Mubarok, 2012) mengatakan penyesuaian sosial dapat diartikan sebagai kemampuan untuk mengubah diri sesuai dengan lingkungan sekitar, ataupun sebaliknya, mengubah lingkungan sesuai dengan keadaan diri individu tersebut. Dimanapun individu berada, individu tersebut akan berhadapan dengan harapan dan tuntutan tertentu dari lingkungan yang harus dipenuhinya. Selain itu, individu juga memiliki kebutuhan, harapan, dan tuntutan yang ada pada dirinya, yang harus diselaraskan dengan tuntutan sehingga dapat diterima di lingkungan sosial.

Menurut Hurlock (1999), penerimaan sosial dapat dicapai apabila remaja mampu untuk menyesuaikan diri terhadap harapan-harapan yang ada dalam kelompok. Bila individu mampu menyelaraskan kedua hal tersebut, maka dapat dikatakan bahwa individu tersebut mampu menyesuaikan diri. Jadi, penyesuaian sosial disimpulkan sebagai cara yang dilakukan oleh individu untuk bereaksi terhadap tuntutan dari dalam diri maupun lingkungannya. Kemampuan dalam melakukan penyesuaian sosial di lingkungan sekolah pada remaja akan tercipta hubungan yang harmonis. Apabila remaja tidak mampu akan mengakibatkan ketidakpuasan pada diri sendiri karena merasa dikucilkan dan mempunyai sikap-sikap menolak diri. Akibatnya remaja tidak mengalami saatsaat yang menggembirakan seperti yang dinikmati oleh teman-teman sebayanya (Hurlock, dalam Maslihah 2011). Terdapat aspek-aspek penyesuaian sosial menurut Hurlock (1999) yaitu penampilan nyata, penyesuaian diri terhadap berbagai kelompok, sikap sosial, dan kepuasan pribadi.

\section{METODE PENELITIAN}

Jenis penelitian ini adalah penelitian korelasional. Populasi dalam penelitian ini adalah seluruh mahasiswa BK UKSW angkatan 2017 yang berjumlah 50 mahasiswa dan menggunakan Teknik total sampling.

Teknik pengumpulan data menggunakan teknik metode skala. Skala terdiri dari 2 jenis yaitu, skala penyesuaian sosial dan skala interaksi teman sebaya. Teknik analisis data yang digunakan dalam penelitian dengan teknik korelasi kendall tau $b$ karena 
bersifat ordinal (Soesilo, 2018), menggunakan SPSS 20 for windows (Statistical Product and Service Solution).

Uji validitas mengacu pada teori Azwar (2012) dengan koefisiensi validitas $<0,20$ yang mengandung arti bahwa item pernyataan tersebut tidak valid atau item pernyataan gugur. Skala penyesuaian sosial sebanyak 43 pernyataan valid dan 2 pernyataan tidak valid. Skala Interaksi teman sebaya sebanyak 39 pernyataan valid dan 1 pernyataan tidak valid. Uji reliabilitas mengacu pada teori Azwar (2000) dengan hasil kedua skala memiliki reliabilitas > 0.8 dan berada pada kategori baik.

\section{HASIL DAN PEMBAHASAN}

Penelitian ini dilakukan pada seluruh mahasiswa BK UKSW angkatan 2017 yang berjumlah 50 mahasiswa dengan rincian sebagai berikut:

Tabel 1. Rincian Jumlah Mahasiswa BK UKSW Angkatan 2017

\begin{tabular}{lc}
\hline Jenis Kelamin & Jumlah \\
\hline Laki-laki & $\mathbf{1 6}$ \\
Perempuan & $\mathbf{3 4}$ \\
Total & 50
\end{tabular}

Mahasiswa BK UKSW angkatan 2017 yang dijadikan subjek penelitian terdiri dari 16 mahasiswa dengan jenis kelamin laki-laki dan 34 mahasiswa dengan jenis kelamin perempuan.
Berdasarkan analisis deskriptif diketahui hasil sebagai berikut:

Tabel 2. Daftar Distribusi Penyesuaian Sosial

\begin{tabular}{|c|c|c|c|}
\hline Kategori & Interval & Frekuensi & $\begin{array}{c}\text { Presentase } \\
(\%)\end{array}$ \\
\hline Sangat & $147-172$ & 1 & $2 \%$ \\
\hline \multicolumn{4}{|l|}{ Tinggi } \\
\hline Tinggi & $121-146$ & 46 & $92 \%$ \\
\hline Sedang & $95-120$ & 3 & $6 \%$ \\
\hline Rendah & $69-94$ & 0 & $0 \%$ \\
\hline Sangat & 43-68 & 0 & $0 \%$ \\
\hline \multicolumn{4}{|l|}{ Rendah } \\
\hline $\begin{array}{l}\text { Tot } \\
\text { al }\end{array}$ & & 50 & $100 \%$ \\
\hline Min & & \multicolumn{2}{|c|}{43} \\
\hline $\operatorname{Max}$ & & \multicolumn{2}{|c|}{172} \\
\hline
\end{tabular}

Berdasarkan dari tabel 2 diketahui penyesuaian sosial mahasiswa dengan kategori sangat tinggi 2\%, tinggi 92\%, sedang $6 \%$, rendah $0 \%$, dan sangat rendah 0\%. Maka dapat disimpulkan bahwa penyesuaian sosial mahasiswa BK UKSW angkatan 2017 dominan berkategori tinggi dengan jumlah mahasiswa 46 dari total 50 mahasiswa.

Tabel 3. Daftar Distribusi Penyesuaian Sosial Kategori Interval Frekuensi Presentase

$(\%)$

\begin{tabular}{|c|c|c|c|}
\hline Sangat & $131-153$ & 0 & $0 \%$ \\
\hline \multicolumn{4}{|l|}{ Tinggi } \\
\hline Tinggi & $108-130$ & 43 & $86 \%$ \\
\hline Sedang & $85-107$ & 7 & $14 \%$ \\
\hline Rendah & $62-84$ & 0 & $0 \%$ \\
\hline Sangat & $39-61$ & 0 & $0 \%$ \\
\hline \multicolumn{4}{|l|}{ Rendah } \\
\hline Total & & 50 & $100 \%$ \\
\hline Min & & & \\
\hline $\operatorname{Max}$ & & & \\
\hline
\end{tabular}


Berdasarkan dari tabel 3 diketahui interaksi teman sebaya mahasiswa dengan kategori sangat tinggi $0 \%$, tinggi $86 \%$, sedang $14 \%$, rendah0\%, sangat rendah 0\%, Maka dapat disimpulkan bahwa interaksi teman sebaya mahasiswa BK UKSW angkatan 2017 dominan berkategori tinggi dengan jumlah siswa 43 dari total 50 siswa.

\section{Uji Hipotesis}

Uji hipotesis bertujuan untuk mengetahui ada atau tidak ada hubungan (korelasi) antara penyesuaian sosial dengan interaksi teman sebaya mahasiswa BK UKSW angkatan 2017. Pengujian korelasi menggunakan kendall's tau $b$ dengan menggunakan SPSS 20.0 for Windows, hasil uji korelasi dapat dilihat pada tabel berikut:

Tabel 4. Analisis Korelasi antara Penyesuaian Sosial Dengan Interaksi Teman Sebaya

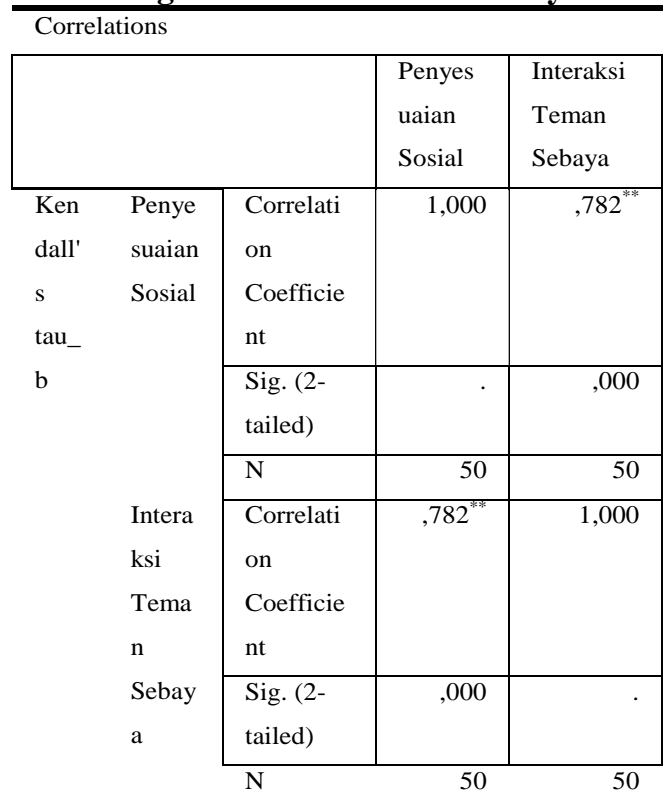

**. Correlation is significant at the 0.05 level (2-tailed).
Berdasarkan hasil uji korelasi diatas maka diketahui nilai $r_{x y}=0,782$ dengan koefesien signifikansi $0,000<0,05$ dengan demikian dapat ditarik kesimpulan bahwa ada hubungan signifikan antara penyesuaian sosial dengan interaksi teman sebaya. Artinya semakin tinggi penyesuaian sosial mahasiswa BK UKSW angkatan 2017, maka semakin tinggi tingkat interaksi teman sebaya yang dimiliki mahasiswa. Atau sebaliknya semakin rendah penyesuaian sosial mahasiswa $\mathrm{BK}$ UKSW angkatan 2017, maka semakin rendah tingkat interaksi teman sebaya yang dimiliki mahasiswa. Menurut Sugiyono (2011) koefisien korelasi 0,782 menunjukkan tingkat hubungan yang kuat. Berdasarkan hasil analisis, didapatkan bahwa hasil koefisiensi korelasi sebesar 0.782 dengan signifikansi sebesar $\mathrm{p}=0.000<0.05$. Nilai signifikansi $0.000<0.05$ menunjukkan hipotesis diterima.

Data yang diperoleh dari 50 responden dan telah dianalisis menggunakan teknik analisis kendall tau $b$. Diketahui hasil dengan nilai $\mathrm{r}=0.782$ dengan signifikansi $0.000<0.05$, dengan demikian dapat ditarik kesimpulan bahwa ada hubungan yang signifikan antara penyesuaian sosial dan interaksi teman 
sebaya pada mahasiswa BK UKSW angkatan 2017dengan tingkat hubungan yang kuat.

Sejalan dengan penelitian terdahulu yang dilakukan oleh Hastuti (2015) tentang Hubungan Antara Interaksi Teman Sebaya dengan Penyesuaian Sosial di SMPN 2 Surakarta dengan $r=$ $0,508, \quad \mathrm{p}=0,001<0,05$ yang menunjukkan bahwa terdapat hubungan yang signifikan antara interaksi teman sebaya dengan penyesuaian sosial. Penelitian lain yang mendukung (2010) tentang Hubungan Antara Penyesuaian Diri dan Persahabatan Pada Teman Sebaya dengan $r=0,332, p=0,000<$ 0,05 yang memiliki hasil yang positif membuktikan bahwa terdapat hubungan yang signifikan antara penyesuaian diri dengan persahabatan teman sebaya.

Schneiders (1964) mengatakan penyesuaian sosial adalah suatu kapasitas atau kemampuan yang dimiliki oleh setiap individu untuk dapat bereaksi secara efektif dan bermanfaat terhadap realitas, situasi, dan relasi sosial, sehingga kriteria yang harus dipenuhi dalam kehidupan sosialnya dapat terpenuhi dengan cara-cara yang dapat diterima dan memuaskan.

Berdasarkan daftar disitribusi Penyesuaian sosial mahasiswa BK
UKSW angkatan 2017 memiliki kategori sangat tinggi $4.3 \%$, tinggi $50 \%$ dan cukup tinggi $45.7 \%$. Dengan demikian dapat disimpulkan bahwa Penyesuaian sosial mahasiswa BK UKSW angkatan 2017 dominan berkategori tinggi dengan jumlah mahasiswa 46 dari total 50 mahasiswa. Diartikan penyesuaian sosial yang dimiliki siswa tinggi sehingga mahasiswa memiliki kemampuan untuk penampilan nyata, penyesuaian diri terhadap berbagai kelompok, memilikisikap sosial, dan memiliki kepuasan pribadi.

Menurut Pierre (2005) interaksi teman sebaya merupakan hubungan individu dengan kelompoknya yang ratarata usia anggota kelompok tersebut hampir sama. Interaksi teman sebaya ditandai dengan adanya keterbukaan, kerjasama, tujuan, serta frekuensi hubungan yang sama sehingga dapat mempengaruhi individu satu sama lain.

Berdasarkan daftar distribusi interaksi teman sebaya diketahui interaksi teman sebaya mahasiswa memiliki kategori sangat tinggi $0 \%$, tinggi $86 \%$, sedang $14 \%$, rendah $0 \%$, sangat rendah $0 \%$, Maka dapat disimpulkan bahwa interaksi teman sebaya mahasiswa BK UKSW angkatan 2017 dominan berkategori tinggi dengan jumlah siswa 43 dari total 
50 siswa. Hal tersebut dapat diartikan bahwa interaksi teman sebaya yang dimiliki mahasiswa tinggi sehingga mahasiswa dapat berkomunikasi dengan baik, beradaptasi dengan lingkungannya, dan dapat mengikuti tuntutan teman sebaya.

Seseorang yang memiliki penyesuaian sosial akan dengan mudah menjalin komunikasi dengan orang lain, terutama dengan teman sebayanya. Sebaliknya jika seseorang tidak memiliki penyesuaian sosial, tentunya akan mengalami kesulitan dalam berkomunikasi seperti misalnya untuk bekerja sama dengan orang lain. Jika seseorang kesulitan dalam berkomunikasi dengan orang lain, maka akan berpengaruh pada proses interaksi teman sebaya.

Berdasarkan hubungan antar kedua variabel didapatkan aspek yang hampir mirip seperti misalnya kekompakan dalam kelompok pada variabel interaksi teman sebaya dan kerjasama dengan kelompok dalam aspek penyesuaian sosial. Hal tersebut yang membuat hasil hasil koefisien korelasi menunjukkan hubungan yang kuat.

Dikaji dari pembahasan di atas dapat diketahui bahwa penyesuaian sosial berhubungan erat dengan interaksi teman sebaya, karena kurangnya penyesuaian sosial yang dimiliki oleh mahasiswa akan dapat menyebabkan kesulitan dalam membina suatu interaksi teman sebaya. Remaja khususnya mahasiswa dituntut untuk memiliki kemampuan dalam berinteraksi dan berdampingan dengan orang lain dalam kurun waktu tertentu. Maka dari itu penyesuaian sosial sangat diperlukan sebagai dasar tercapainya proses interaksi teman sebaya yang baik.

\section{PENUTUP}

\section{Simpulan}

Berdasarkan hasil yang diperoleh dalam penelitian ini, maka dapat disimpulkan bahwa ada hubungan yang signifikan antara penyesuaian sosial dengan interaksi teman sebayamahasiswa BK UKSW Angkatan 2017 dengan hasil nilai $r=0,782$ (tingkat hubungan kuat) dengan signifikansi $0.000<0.05$.

\section{Saran}

Berdasarkan hasil penelitian, penulis mengemukakan saran-saran sebagai berikut:

Program studi BK perlu memastikan mahasiswanya aktif dalam proses perkuliahan di kelas terutama pada saat mata kuliah yang berkaitan dengan penyesuaian sosial maupun interaksi dengan lingkungan seperti misalnya Komunikasi Antar Pribadi, BK Pribadi 
dan Sosial, Bimbingan Kelompok, dan mata kuliah yang berhubungan dengan sikap sosial. Selain itu program studi juga wajib mendorong kegiatan diluar perkuliahan untuk meningkatkan kebutuhan penyesuaian sosial dan interaksi teman sebaya seperti makrab, outbond dan study tour yang disusun dengan menarik untuk menambah keterampilan dalam berinteraksi. Hal ini perlu dilakukan karena apabila dilihat dari fenomena yang ada, masih banyak mahasiswa yang kurang memiliki minat untuk mengikuti kegiatan di luar perkuliahan. Maka dari itu program studi melalui dosen dan lembaga kemahasiswaan hendaknya dapat lebih menggali pokok masalah yang menyebabkan kurangnya minat mahasiswa dalam mengikuti kegiatan tersebut. Mengingat nantinya mahasiswa BK akan menjadi seorang guru pembimbing yang juga akan memberikan layanan bimbingan maupun konseling, maka sikap penyesuaian sangat dibutuhkan guna memiliki interaksi yang baik pula.

Berdasakan hasil temuan dalam penelitian ini, penulis menyarankan agar peneliti selanjutnya dapat meneliti mengenai penyesuaian sosial dan interaksi teman sebaya pada popolasi yang lebih luas, dan mempertajam variable agar hasil yang didapatkan lebih bervariasi. Selain itu perlu penelitian pada subjek penelitian pada program studi yang berbeda agar hasilnya dapat dibandingkan.

\section{DAFTAR PUSTAKA}

Aristya, D.N. dan Anizar Rahayu. 2018. Hubungan Dukungan Sosial dan Konsep Diri dengan Penyesuaian Diri Remaja Kelas X SMA Angkasa I Jakarta. IkraithHumaniora, Vol. 2 No. 2

Azwar, S. 2015. Metode Penelitian. Yogyakarta: Pustaka Pelajar

Estiane, Uthia. 2015. Pengaruh Dukungan Sosial Sahabat Terhadap Penyesuaian Sosial Mahasiswa Baru di Lingkungan Perguruan Tinggi. Jurnal Psikologi Klinis dan Kesehatan Mental. Vol. 4, No. 1

Hurlock, E.B. 1999. Psikologi Perkembangan: Suatu Pendekatan Sepanjang Rentang Kehidupan. Jakarta: Penerbit Erlangga

Papalia, E.D. 2009. Human Development: Perkembangan Manusia. Jakarta: Salemba Humanika

Pierre, F. 2005. Peer Interaction in The Haitian Public School Context. Thesis.

Santrock, J.W. 2007. Perkembangan Anak. Jakarta: Penerbit Erlangga

Schneiders. 1984. Personal Adjustment and Mental Heatlh. New York: Holt, Rinehart and Winston 
